\title{
Chromatographic determination of siphonodin content: A rapid and simple strategy for discriminating between Hemsleya omeiensis and other sources of Xuedan
}

\author{
Yi Qin ${ }^{1}$, Hong-ling Zhang ${ }^{1}$, Jin Wang ${ }^{1}$, Qin-wan Huang ${ }^{1 *}, \mathrm{Ji}-$ lin Sun ${ }^{2}$, Ren-chuan \\ $\mathrm{YaO}^{2}$ \\ ${ }^{1}$ College of Pharmacy, Chengdu University of Traditional Chinese Medicine, Chengdu 611137, ${ }^{2}$ Sichuan Fuzheng Pharm. Co., \\ Ltd, Chengdu 610041, China
}

*For correspondence: Email: huangqinwan@cdutcm.edu.cn

\begin{abstract}
Purpose: To develop a rapid and simple siphonodin content-based high performance liquid chromatography (HPLC) method to distinguish Hemsleya omeiensis from other sources of xuedan. Methods: Siphonodin was isolated from Hemsleya omeiensis and identified by $x$-ray crystallographic analysis. An optimized HPLC method was applied for the determination of siphonodin contents of $H$. omeiensis, $H$. dolichocarpa and $H$. gigantha.

Results: Siphonodin was successfully separated by the optimized HPLC method in $<10$ min, and the results of validation showed that the HPLC method was stable and very accurate for the quantification of siphonodin. The mean content of siphonodin in 10 batches of $\mathrm{H}$. omeiensis was $3.78 \mathrm{mg} / \mathrm{g}$, but the compound was not detectable in $\mathrm{H}$. dolichocarpa and $\mathrm{H}$. gigantha using the developed HPLC method. Conclusion: These results indicate that the developed HPLC method is suitable for distinguishing $\mathrm{H}$. omeiensis from other sources of xuedan.
\end{abstract}

Keywords: Xuedan, Hemsleya omeiensis, Hemsleya giganth, Hemsleya dolichocarpa, Siphonodin, Discrimination

\begin{abstract}
This is an Open Access article that uses a fund-ing model which does not charge readers or their institutions for access and distributed under the terms of the Creative Commons Attribution License (http://creativecommons.org/licenses/by/4.0) and the Budapest Open Access Initiative (http://www.budapestopenaccessinitiative.org/read), which permit unrestricted use, distribution, and reproduction in any medium, provided the original work is properly credited.

Tropical Journal of Pharmaceutical Research is indexed by Science Citation Index (SciSearch), Scopus, International Pharmaceutical Abstract, Chemical Abstracts, Embase, Index Copernicus, EBSCO, African Index Medicus, JournalSeek, Journal Citation Reports/Science Edition, Directory of Open Access Journals (DOAJ), African Journal Online, Bioline International, Open-J-Gate and Pharmacy Abstracts
\end{abstract}

\section{INTRODUCTION}

It is known that herbal medicines are beneficial for protecting humans from diseases, and they are important sources of new drugs for the cure and prevention of diseases [1,2]. In Chinese folk medicine, xuedan is a traditional herbal medicine used for clearing heat and removing toxins. It has for long been widely used in clinics as a folk and conventional herb for the treatment of ulcers, bacillary dysentery and all kinds of inflammations $[3,4]$. Xuedan is derived mainly from three varieties of Hemsleya: Hemsleya omeiensis, Hemsleya gigantha and Hemsleya dolichocarpa. Compared with other varieties, Hemsleya omeiensis is not bitter, and it is associated with better clinical compliance and high price. Several studies have reported appreciable differences in compositions among the three sources of xuedan, especially in their bitter taste [5-8]. 
However, it is usually difficult to distinguish them in morphology when these medicinal herbs are dried. Previous studies revealed that xuedan contains chikusetsu saponin IVa, hemslosides $\mathrm{Ma}_{1}$, hemslosides $\mathrm{G}_{1}$, hemslosides $\mathrm{H}_{1}$, dihydrocucurbitacin F-25-O-acetate, dihydrocucurbitacin $\mathrm{F}$ and oleanolic acid-3-O-aL-arabinopyranosyl glucurropyranoside E [7]. Siphonodin [4-hydroxymethyl-2 $(5 \mathrm{H})$-furanone] is a natural compound found in a variety of Euonymus leaves and small nest moths, and it has also been isolated from Rambutan seeds and $H$. Ellipsoidea [9-11]. It is one of the 2(5)furanone compounds structurally similar to the bacterial quorum sensing system signaling molecule $\mathrm{N}$-acyl homoserine lactone $(\mathrm{AHL})$, and it is widely studied as bacterial quorum sensing inhibitor [12-14]. Previous studies reported that siphonodin exerted bacterial biofilm inhibitory activity against Pseudomonas aeruginosa, and that its structure can be modified [15]. Consequently, the aim of this study was to develop a rapid and simple siphonodin contentbased HPLC method for distinguishing $H$. omeiensis from other sources of xuedan.

\section{EXPERIMENTAL}

\section{Plant materials, processing and reagents}

Fresh tubers of $H$. omeiensis and $H$. dolichocarpa were collected at Emei Mount and Peng County, respectively, in Sichuan Province of China, in May 2017. Fresh tubers of $H$. gigantha were collected at Shimian County, Sichuan Province of China in August 2017. The samples were identified by Prof Yue-cheng Li, a taxonomist at the Sichuan Institute for Food and Drug Control, Chengdu, China. Voucher specimens were deposited in the herbarium of the College of Pharmacy, Chengdu University of Traditional Chinese Medicine, Chengdu, China. Fresh, whole tubers were cut into slices and oven-dried at $55{ }^{\circ} \mathrm{C}$. The dried tubers were ground with a universal high-speed milling machine (Bingdu Electric Co. Ltd, Shanghai, China), and then sieved through a 65 mesh prior to use in subsequent experiments. The water used was purified with a UPH-1-10T model water purifier system (Chengdu ultrapure Technology Co., Ltd, China). All other chemicals were of HPLC or reagent grade. Silica gel $(200-300$ mesh, and 60 - 80 mesh) were supplied by Qingdao Marine Chemical Corporation, China.

\section{Sample purification}

For thin layer chromatography (TLC) analysis, powdered tuber $(2 \mathrm{~g})$ was dissolved with $20 \mathrm{~mL}$ of methanol in a tightly sealed conical flask. It was then subjected to ultrasonic processing for $40 \mathrm{~min}$, and filtered. Thereafter, $10 \mathrm{~mL}$ of the filtrate was concentrated to $4 \mathrm{~mL}$. For HPLC analysis, powdered tuber $(0.2 \mathrm{~g})$ was weighed precisely and placed in a weighed $50 \mathrm{~mL}$ conical flask to which HPLC-grade methanol $(25 \mathrm{~mL})$ was added, and the flask and contents were subjected to ultrasonic treatment for $30 \mathrm{~min}$. On cooling and weighing, some methanol $(\mathrm{MeOH})$ was added, with shaking, and the solution was through $0.45 \mu \mathrm{m}$ polytetrafluoroethylene filter before injection.

\section{TLC analysis}

The TLC separations were performed on $G$ plates (Qingdao Marine Chemical Corporation, China). The sample solutions (5 $\mu \mathrm{L})$ were applied at the origin on the TLC plate, and developed with petroleum ether/ethyl acetate/methanol at a volume ratio of $5: 1: 0.5$. The developed plates were air-dried and the spots were made visible by spraying with $2 \%$ vanillic aldehyde in $10 \%$ ethanol sulfate solution, followed by heating at $105{ }^{\circ} \mathrm{C}$ for $2 \mathrm{~min}$. The spots were visualized at $365 \mathrm{~nm}$ in a UV trans-illuminator (Baoshan Gucun Electro Optic Instrument Factor, Shanghai, China).

\section{Extraction and isolation of siphonodin}

The powdered tubers of $H$. omeiensis $L$. T. Shen. et. W.J. Chang $(1.04 \mathrm{~kg})$ were extracted 7 times with methanol $(\mathrm{MeOH})$ under reflux $(\mathrm{MeOH} 4 \mathrm{~L} x$ 7, $6 \mathrm{~h}$ each), and filtered. After evaporation of the solvent under reduced pressure, the $\mathrm{MeOH}$ extract $(217 \mathrm{~g})$ was dissolved in warm water and then partitioned in ethyl acetate (EtOAc). The EtOAc fraction (34 g) was subjected to silica gel column chromatography with a gradient elution system of petroleum ether: EtOAc (10:1, 8:1, 5:1, $3: 1$, and $1: 1 \mathrm{v} / \mathrm{v}$ ) to give eight fractions (Fr.A Fr.H). The combined Fr.F $(17 \mathrm{~g})$ was rechromatographed over silica gel using petroleum ether: EtOAc $(3: 1,1: 1 \mathrm{v} / \mathrm{v})$ to give three fractions (Fr.I -FrllI). The Fr.III (14 g) was recrystallized from petroleum ether to give siphonodin $(12 \mathrm{~g})$.

\section{HPLC analysis}

\section{Instrument and chromatographic conditions}

The HPLC separations were carried out on a Shimadzu LC-2030C3 D model instrument (Shimadzu Corp., Kyoto Japan) using a reversephase Shim-pack GIST $\mathrm{C}_{18}(250 \times 4.6 \mathrm{~mm}, 5 \mu \mathrm{m})$ column (Shimadzu Corp., Kyoto Japan) at a column temperature of $30^{\circ} \mathrm{C}$. The samples were eluted that using a gradient program of the mixture of acetonitrile and $0.1 \%$ phosphoric acid 
(Table 1). The flow rate was $0.8 \mathrm{~mL} / \mathrm{min}$, and the sample injection volume was $5 \mu \mathrm{L}$. The UV detection wavelength was set at $210 \mathrm{~nm}$.

Table 1: Gradient elution program

\begin{tabular}{lcc}
\hline $\begin{array}{l}\text { Time } \\
(\mathbf{m i n})\end{array}$ & PAA & Acetonitrile (\%) \\
\hline 0.01 & 95 & 5 \\
10 & 90 & 10 \\
\hline
\end{tabular}

\section{Preparation of standard solution}

The standard solution was prepared with siphonodin dissolving in methanol to a final concentration of $0.2224 \mathrm{mg} / \mathrm{mL}$.

\section{Method validation}

The method validation contains for linearity and range, limit of detection (LOD) and limit of quantification (LOQ), accuracy, precision, and recovery test [16].

\section{Linearity assessment}

Linearity of the method was obtained by the determination of the peak area of the same reference solution with sample sizes of $1,2,3,5$, 7,9 and $10 \mu \mathrm{L}$. Calibration curves were constructed by plotting the peak areas against the corresponding concentrations of the compound. The regression equation was calculated by using the reference quantity of the control sample as the horizontal axis $(x)$, and the peak area of the chromatogram as the ordinate (y).

\section{Precision assessment}

The precision was obtained by injecting the same reference solution of $5 \mu \mathrm{l}$ sample size 6 times into the HPLC column. From the areas obtained, the $\%$ relative standard deviation (RSD) value for siphonodin was calculated.

\section{Repeatability}

The repeatability was obtained from six copies of determinations of a $5-\mu \mathrm{L}$ sample solution (SI) from $H$. Omeiensis. The RSD was calculated based on the mass fraction of siphonodin.

\section{Solution stability}

Stability was tested with one sample solution stored at room temperature at several time points $(0,3,6,9,12,15,18$ and $24 \mathrm{~h})$ after preparation, and the RSD values were calculated. The sample size used was $5 \mu \mathrm{L}$.

\section{Recovery test}

Six samples (S6, $0.1 \mathrm{~g})$ of $H$. omeiensis, determined already, were weighed precisely. Then, $1 \mathrm{~mL}$ reference solution in which the concentration of the siphonodin was 2.251 $\mathrm{mg} / \mathrm{mL}$ was added to each sample. Using the above method of sample preparation to make one concentration level (100\%), the peak areas of mixed reference solutions were determined, with sample size of $5 \mu \mathrm{L}$, and the recovery was obtained. The average recovery was estimated as percentage of analyte.

\section{Limits of detection and of quantification}

The LOD and LOQ values were the corresponding concentrations when the signal-tonoise ratio was $3: 1$ and 10:1.

\section{RESULTS}

\section{TLC differentiated $H$. omeiensis from other Xuedan}

For TLC analysis, three sources of Xuedan were extracted in methanol, and the reference compound was dissolved in methanol and applied on the bottom of a silica gel-coated TLC plates as spots. Under the experimental condition, a light green fluorescence spot appeared only in the samples of $H$. omeiensis under $365 \mathrm{~nm}$ with retention factor (Rf) of 0.53 (Figure 1). For the samples of $H$. dolichocarpa and $H$. gigantha, the signal at $\operatorname{Rf} 0.53$ was absent. It was observed that 25-O-acetyl-23,24dihydrocucurbitacin $\mathrm{F}$ and 23, 24dihydrocucurbitacin $F$ appeared as yellow spots under the fluorescent lamp and $365 \mathrm{~nm}$, with Rf values of 0.68 and 0.39 , respectively. The yellow spots occurred at Rf of 0.68 and Rf of 0.39 for $H$. dolichocarpa and $H$. gigantha, respectively when their bitter tubers were extracted in methanol, whereas the yellow spots with $\mathrm{Rf}$ values of 0.0 .68 and 0.39 were absent in the samples of $H$. omeiensis.

\section{Identification of compounds}

Siphobodin: $\mathrm{C}_{5} \mathrm{H}_{6} \mathrm{O}_{3}$, light yellow crystal (petroleum ether). The absolute configurations of this compound were identified by X-ray crystallographic analysis (Figure 2). Comparing the published physical and NMR data, the compound was siphonodin [4-hydroxymethyl$2(5 \mathrm{H})$-furanone] [17]. This structurally simple butenolide was first isolated from $\mathrm{H}$. omeiensis while it was reported that siphonodin in the 
Hemsleya genus was first isolated from $H$. ellipsoidea.

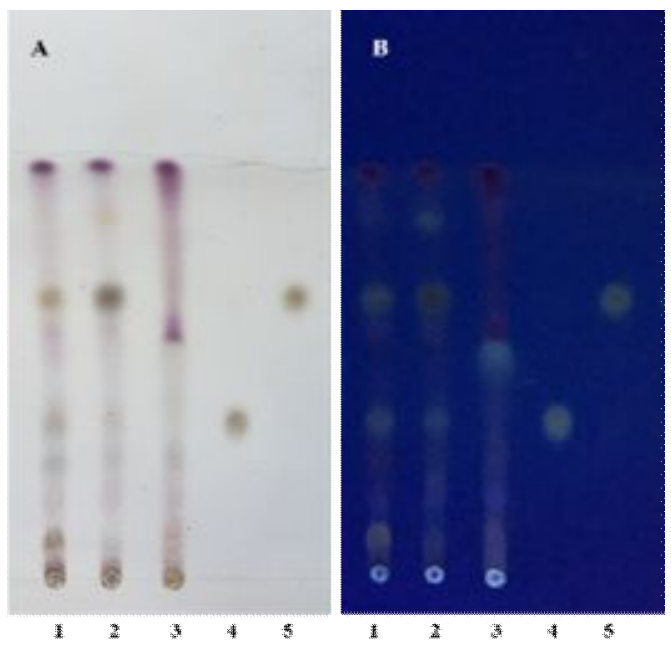

Figure 1: TLC identification of three sources of Xuedan. The plate was visualized under fluorescent lamp (A), and at $365 \mathrm{~nm}(\mathrm{~B})$. TLC samples were prepared by methanol extraction. $H$. dolichocarpa (lane 1); $H$. gigantha, (lane 2); H. Omeiensis (lane 3); 23, 4-dihydrocucurbitacin $\mathrm{F}$ (lane 4 ) and 25-O-acetyl23,24-dihydrocucurbitacin F 9lane 5)

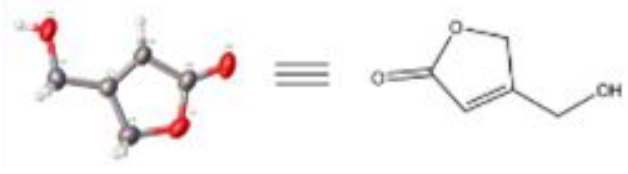

Figure 2: ORTEP representation of siphonodin

\section{Method validation results}

\section{Linearity}

Linear calibration curves of siphonodin were obtained over the calibration range of 0.2224 $2.224 \mu \mathrm{g}$. The linear regression equation was: $y=7,056527.51 x+83684.35 \ldots \ldots$ (1) $\left(r^{2}=\right.$ 0.9998 for siphonodin).

\section{Precision}

In the precision test, the RSD value of the peak area of the siphonodin was $0.33 \%$, which indicated that the instrument had high precision.

\section{Repeatability}

In the repeatability test, the RSD values of each component was less than $0.99 \%$, indicating that the method had good repeatability.

\section{Solution stability}

In the stability test, the RSD value of siphonodin was $0.64 \%$. The solution stability results showed that peak area of siphonodin remained approximately unchanged up to $24 \mathrm{~h}$ : no significant degradation was observed within the indicated period.

\section{Recovery}

In the recovery test, average recovery was $96.50 \%$ and RSD value was $1.34 \%$, as shown in Table 2.

\section{Limits of detection and of quantification}

The LOD and LOQ for siphonodin were estimated at signal-to-noise ratios of $3: 1$ and $10: 1$ as $0.0741 \mathrm{ng}$ and $0.2964 \mathrm{ng}$, respectively.

\section{Content of siphonodin in three sources of Xuedan}

The results of analysis of 30 batches of samples in the three sources of xuedan revealed that siphonodin was detected only in $H$. omeiensis, while there was no chromatographic evidence of siphonodin in $H$. gigantha and $H$. dolichocarpa (Figure 3). Thus, the new HPLC-UV method for determination of siphonodin would be useful for discriminating between $H$. omeiensis and other sources of xuedan.

Under the above chromatographic conditions, chromatographic peaks of the sample solution and reference solution had the same retention time. The degree of separation of siphonodin in all samples was greater than 1.5 , the theoretical plates were greater than 60000 , and the method gave good specificity.

Table 2: Recovery of the HPLC method for determination of siphonodin

\begin{tabular}{lccccc}
\hline $\begin{array}{l}\text { Original } \\
\text { found }\end{array}$ & $\begin{array}{c}\text { Amount spiked } \\
(\mathbf{m g})\end{array}$ & $\begin{array}{c}\text { Amount } \\
\text { found }\end{array}$ & $\begin{array}{c}\text { Recovery } \\
(\%)\end{array}$ & $\begin{array}{c}\text { Mean } \\
\text { recovery (\%) }\end{array}$ & RSD (\%) \\
\hline 2.1418 & 2.251 & 4.078 & 97.42 & & \\
2.1418 & 2.251 & 4.038 & 95.32 & & \\
2.1418 & 2.251 & 4.103 & 98.40 & 96.50 & 1.34 \\
2.1418 & 2.251 & 4.038 & 95.30 & & \\
2.1418 & 2.251 & 4.047 & 95.59 & & \\
2.1418 & 2.251 & 4.076 & 96.96 & & \\
\hline
\end{tabular}




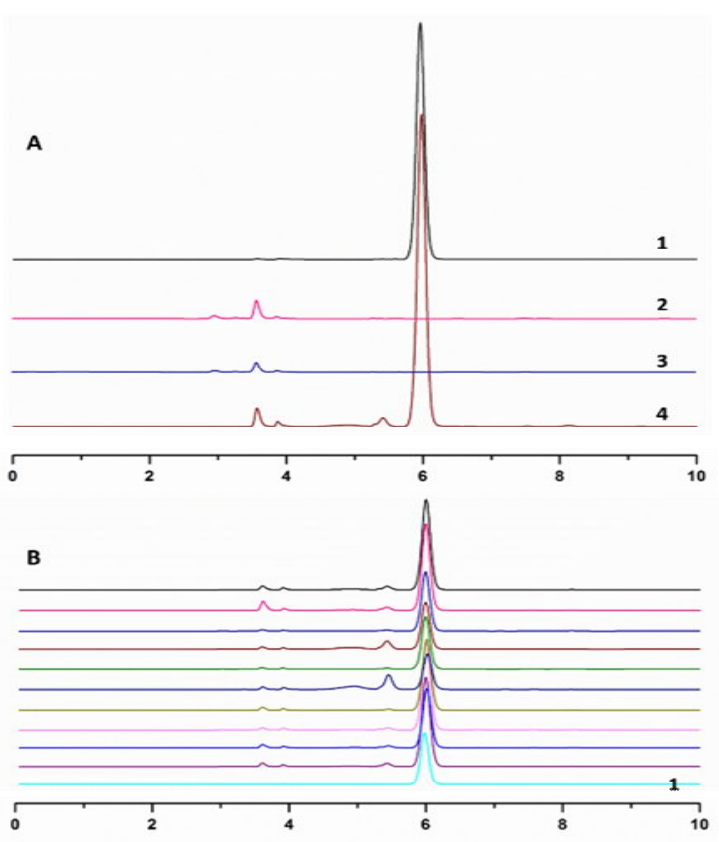

Figure 3: HPLC chromatograms: comparison of three sources Xuedan (A) and 10 batches of test samples from $H$. omeiensis (B); 1 - 4 in Figure A represent siphonodin, $H$. dolichocarpa,$H$. gigantha and $H$. omeiensis respectively

The quantitative results on siphonodin from the 30-batch samples in the HPLC-PDA assays are shown in Table 3. In $\mathrm{H}$. omeiensis, the average content of siphonodin was $3.78 \mathrm{mg} / \mathrm{g}$. However, the contents of siphonodin in $\mathrm{H}$. dolichocarpa and $H$. gigantha were $2.02 \times 10^{-3}$ and $1.56 \times 10^{-3}$ $\mathrm{mg} / \mathrm{g}$, respectively, and were approximately below the limit of quantitation. Therefore, siphonodin content could be a marker for identification of $H$. omeiensis.

Table 3: Content of siphonodin from the three sources of xuedan

\begin{tabular}{lccc}
\hline No. & $\begin{array}{c}\boldsymbol{H} . \\
\text { omeiensis } \\
(\mathbf{m g} / \mathbf{g})\end{array}$ & $\begin{array}{c}\boldsymbol{H} . \text { dolichocarpa } \\
(\mathbf{m g} / \mathbf{g})\end{array}$ & $\begin{array}{c}\boldsymbol{H} \text {. gigantha } \\
(\mathbf{m g} / \mathbf{g})\end{array}$ \\
\hline S1 & 4.14 & $0.90 \times 10^{-3}$ & $1.69 \times 10^{-3}$ \\
S2 & 4.73 & $2.34 \times 10^{-3}$ & $2.73 \times 10^{-3}$ \\
S3 & 3.66 & $1.82 \times 10^{-3}$ & $1.00 \times 10^{-3}$ \\
S4 & 3.04 & $2.11 \times 10^{-3}$ & $2.07 \times 10^{-3}$ \\
S5 & 3.23 & $1.99 \times 10^{-3}$ & $0.81 \times 10^{-3}$ \\
S6 & 2.14 & $1.77 \times 10^{-3}$ & $0.81 \times 10^{-3}$ \\
S7 & 3.97 & $4.49 \times 10^{-3}$ & $1.31 \times 10^{-3}$ \\
S8 & 4.30 & $1.92 \times 10^{-3}$ & $1.18 \times 10^{-3}$ \\
S9 & 3.49 & $1.29 \times 10^{-3}$ & $2.67 \times 10^{-3}$ \\
S10 & 5.11 & $1.52 \times 10^{-3}$ & $1.34 \times 10^{-3}$ \\
Mean & 3.78 & $2.02 \times 10^{-3}$ & $1.56 \times 10^{-3}$ \\
\hline
\end{tabular}

\section{DISCUSSION}

In a previous study, 25-O-acetyl-23,24dihydrocucurbitacin $\mathrm{F}$ and 23, 24-dihydrocucurbitacin $\mathrm{F}$ were identified as responsible for the bitter taste in xuedan [18]. These cucurbitacins are usually used as markers of quality control, and for distinguishing between various xuedans [19]. However, these compounds are not suitable markers for $H$. omeiensis. From the results obtained in this study, the light green spot with Rf 0.53 was set as a specific marker for the identification of $H$. omeiensis. This was the basis of subsequent guided isolation using TLC analysis.

Analysis of siphonodin in 30-batch samples from three sources of xuedan revealed that siphonodin was detected only in $H$. omeiensis. Chromatographic characteristics of siphonodin were absent in $H$. gigantha and $H$. dolichocarpa. Thus, this new HPLC-UV method for determination siphonodin would be useful for distinguishing $\mathrm{H}$. omeiensis from other xuedan sources.

\section{CONCLUSION}

A simple, selective, accurate and durable HPLC method for the determination of siphonodin contents of xuedan has been successfully developed. The developed method is the first reported HPLC method for the analysis of siphonodin contents of three sources of xuedan. The results of the analysis of the xuedan samples suggest that this method can be applied for the successful identification of crude drugs from $\mathrm{H}$. omeiensis.

\section{DECLARATIONS}

\section{Acknowledgement}

This work was supported by Science and Technology Plan Projects in Sichuan Province. Technical Standards and Technical Specifications and Quality Standards for Innovative Processing of Xuedan (no. 2015SZ0107)

\section{Conflict of interest}

No conflict of interest is associated with this study.

\section{Authors' contribution}

We declare that this work was done by the authors named in this article and all liabilities pertaining to claims relating to the content of this article will be borne by the authors. QWH is corresponding author on the study. YQ was first author and responsible for collecting materials, 
doing experiment, writing the paper. JLS and JW edited in the article pictures. HLZ and QWH analyzed the article and made recommendations. RCY provided samples. All authors read and approved the final manuscript.

\section{Open Access}

This is an Open Access article that uses a funding model which does not charge readers or their institutions for access and distributed under the terms of the Creative Commons Attribution License (http://creativecommons.org/licenses/by/ 4.0) and the Budapest Open Access Initiative (http://www.budapestopenaccessinitiative.org/rea d), which permit unrestricted use, distribution, and reproduction in any medium, provided the original work is properly credited.

\section{REFERENCES}

1. Peng $W$, Shen $H$, Lin B, Han P, Li C, Zhang Q, Ye B, Rahman $K$, Xin $H$, Qin $L$, et al. Docking study and antiosteoporosis effects of a dibenzylbutane lignan isolated from Litsea cubeba targeting Cathepsin $\mathrm{K}$ and MEK1. Med Chem Res 2018; 27: 2062-2070.

2. Yue $R$, Shan $L$, Yang $X$, Zhang $W$. Approaches to target profiling of natural products. Curr Med Chem 2012; 19 : 3841-3855.

3. Kasai R. Studies on the constituents of cucurbitaceous plants. Yakugaku Zasshi 2008; 128: 1369-1382.

4. Nie RL, Morita T, Kasai R, Zhou J, Wu CY, Tanaka O. Saponins from Chinese medicinal plants. (I). Isolation and structures of hemslosides. Planta Med 1984; 50 : 322-327.

5. Chen Y, Qiu MH, Gu K, Chen JC. A New Cucurbitacin and $A$ New Oleanolic Acid Glycosides from Hemsleya gigantha. Acta Botanica Yunnanica 2003; 25(05): 613619.

6. Shi $Y Q$, Yang $P Q$, Chen L, Zhang WJ. Studies on the chemical Constituents of Emeixuedan (Hemsleya omeiensis). Chinese Traditional and Herbal Drugs 1995; 26: 619-621+672.

7. Shi $Y Q$, Yang $P Q$, Nie RL. Two saponins isolated from Hemsleya dolichocarpa. Acta Botanica Yunnanica 1990; 12: $460-462$.
8. Zhang $H L$, Qin $Y$, Zeng HR, Huang $Q W$, Sun JL, Yao RC Comparative studies on the toxicological, antiinflammatory and analgesic properties of three sources of Xudan in mice and their rapid identification by electronic tongue. Trop J Pharm Res 2019; 18: 257-262.

9. Fung SY, Herrebout WM, Verpoorte R, Fischer FC. Butenolides in small ermine moths, Yponomeuta spp. (Lepidoptera: Yponomeutidae), and spindle-tree, Euonymus europaeus (Celastraceae). J Chem Ecol 1988; 14: 1099-1111.

10. Ragasa CY, de Luna RD, Cruz WC, Jr., Rideout JA. Monoterpene lactones from the seeds of Nephelium lappaceum. J Nat Prod 2005; 68: 1394-1396.

11. Hano $Y$, Ya-Qin S, Nomura T, Pei-Quan $Y$, Wen-Jin C. Two acetogenins from Hemsleya ellipsoidea. Phytochem 1997; 46: 1447-1449.

12. Musk DJ Jr, Hergenrother PJ. Chemical countermeasures for the control of bacterial biofilms: effective compounds and promising targets. Curr Med Chem 2006; 13: 2163-2177.

13. Han Y, Hou S, Simon KA, Ren D, Luk YY. Identifying the important structural elements of brominated furanones for inhibiting biofilm formation by Escherichia coli. Bioorg Med Chem Lett 2008; 18: 1006-1010.

14. Kim C, Kim J, Park HY, Park HJ, Lee JH, Kim CK, Yoon J. Furanone derivatives as quorum-sensing antagonists of Pseudomonas aeruginosa. Appl Microbiol Biotechnol 2008; 80: 37-47.

15. Wang $Y Z$, Ye CQ, Liu GY, Sun $P H$, Chen WM. Synthesis of 4-(hydroxymethyl)-2(5H)-furanone and its effect on the biofilms of Pseudomonas aeruginosa. Chem Reagents 2010; 32: 970-972.

16. Shinjyo $N$, Fuchino $H$, Kawahara $N$, Hishida $A$. Determination of ( $E$ )-ferulic acid content in the root of angelica acutiloba: a simple chemical evaluation method for crude drug quality control. J Nat Medicin 2018; 72: 774-778.

17. Nie RL, Chen ZL. The research history and present status on the chemical components of genus Hemsleya (Cucurbitaceae). Acta Botanica Yunnanica 1986; 8: 115124.

18. $L I Y, X u X T$, Zheng ZF, Li L, Yao QQ. Research progress on chemical constituents and biological activities of plants from Hemsleya Cogn. Chin Trad Herbal Drugs 2015; 46: 2800-2808.

19. Wagner $H$, Flitsch $K$. New monocyclic lactones from Siphonodon australe (author's transl). Planta Med 1981; 43: $245-248$. 